\title{
Ameliorative efficacy of quercetin against cisplatin-induced mitochondrial dysfunction: Study on isolated rat liver mitochondria
}

\author{
MOHAMMAD WASEEM ${ }^{1 *}$, HEENA TABASSUM $^{2 *}$, MONICA BHARDWAJ $^{1}$ and SUHEL PARVEZ ${ }^{1}$ \\ Departments of ${ }^{1}$ Medical Elementology and Toxicology and ${ }^{2}$ Biochemistry, \\ Jamia Hamdard (Hamdard University), New Delhi 110062, India
}

Received April 17, 2016; Accepted October 21, 2016

DOI: $10.3892 / \mathrm{mmr} .2017 .6860$

\begin{abstract}
The present study aimed to investigate the hepatoprotective effects of the bioflavonoid quercetin (QR) on cisplatin $(\mathrm{CP})$-induced mitochondrial oxidative stress in the livers of rats, to elucidate the role of mitochondria in CP-induced hepatotoxicity, and its underlying mechanism. Isolated liver mitochondria were incubated with $100 \mu \mathrm{g} / \mathrm{ml} \mathrm{CP}$ and/or $50 \mu \mathrm{M}$ QR in vitro. $\mathrm{CP}$ treatment triggered a significant increase in membrane lipid peroxidation (LPO) levels, protein carbonyl (PC) contents, and a decrease in reduced glutathione (GSH) and non-protein thiol (NP-SH) levels. In addition, CP caused a marked decline in the activities of enzymatic antioxidants and mitochondrial complexes (I, II, III and V) in liver mitochondria. QR pre-treatment significantly modulated the activities of enzymatic antioxidants and mitochondrial complex enzymes. Furthermore, QR reversed the alterations in LPO and PC levels, and GSH and NP-SH contents in liver mitochondria. The results of the present study suggested that QR supplementation may suppress CP-induced mitochondrial toxicity during chemotherapy, and provides a potential prophylactic and defensive candidate for anticancer agent-induced oxidative stress.
\end{abstract}

\section{Introduction}

Chemotherapy is an important cancer treatment and numerous anti-cancer agents have been developed. However, the adverse effects and systemic toxicity induced by these agents limits their application $(1,2)$. Cisplatin (cisdiamminedichloroplatinum II; CP) is a platinum-containing anticancer therapeutic

Correspondence to: Dr Suhel Parvez, Department of Medical Elementology and Toxicology, Jamia Hamdard (Hamdard University), Hamdard Nagar, New Delhi 110062, India

E-mail: sparvez@jamiahamdard.ac.in

${ }^{*}$ Contributed equally

Key words: cisplatin, quercetin, mitochondria, antioxidants, mitochondrial stress that is used for the treatment of various human carcinomas, including head, oral, lung and neck cancer, metastatic tumors of testis and ovaries, progressed bladder cancer and other solid tumors. The exact mechanism underlying CP-induced toxicity remains to be fully elucidated. Previous studies have demonstrated that the anticancer behavior of CP originates from its capacity to attach to the N-7 position of purine bases of cellular DNA causing mono-adducts formation, which are converted into inter- and intra-strand cross links with a reaction at the secondary reactive site of drug together with the second nucleobase (3-5). Mitochondria have been revealed to be the cellular power plants $(6,7)$. A direct association between mitochondrial dysfunction and the toxicity of chemotherapeutic agents has been demonstrated (8), and mitochondria are now considered anticancer drug targets. Previous in vitro studies have revealed that CP-treated rat hepatic cells undergo alterations to mitochondrial structure and function $(9,10)$. These alterations may be crucial in strengthening various aspects of $\mathrm{CP}$ hepatotoxicity. Natural antioxidants have been investigated as potential nutraceuticals to minimize the adverse effects and increase the efficacy of chemotherapeutic agents (11). Quercetin (3,3', 4', 5,7-pentahydroxyflavone; QR) is a large class of polyphenolic compounds ubiquitously present in plants and food sources. It is primarily present in vegetables, fruits, red wine, tea and other aromatic plants (12). QR has been investigated as a therapeutic agent to ameliorate various toxicities, including nephrotoxicity (13), cardiotoxicity (14), neurotoxicity (15) and hepatotoxicity (16).

In addition, QR has been reported to contribute to various pharmacological and biological activities, including antimicrobial (17), antioxidant (18), anti-inflammatory (19) and anticancer activities (20). It has been demonstrated to inhibit oxidative stress-induced mitochondrial damage (21). The present study aimed to investigate the effects of QR on $\mathrm{CP}$-induced mitochondrial dysfunction using an in vitro model.

\section{Materials and methods}

Chemicals. 4-amino-3-hydroxy-1-naphtalenesulfonic acid (ANSA), bovine serum albumin (BSA), butylated hydroxy toluene (BHT), 1-chloro-2, 4 dinitrobenzene (CDNB), 2,6, dichlorophenol indophenols (DCIP), 2,4-dinitrophenyl 
hydrazine (DNPH), 5,5'-dithiobis (2-nitrobenzoicacid) (DTNB), ethylenediaminetetraacetic acid (EDTA), ethylene glycol-O, -O'-bis, (2-Aminoethyl) tetraacetic acid epinephrine, reduced glutathione (GSH), hydrogen peroxide $\left(\mathrm{H}_{2} \mathrm{O}_{2}\right)$, nicotinamide adenine dinucleotide reduced (NADH), nicotinamide adenine dinucleotide phosphate reduced tetra sodium salt (NADPH), o-phoshoric acid (OPA), thiobarbituric acid (TBA) and trichloro acetic acid (TCA) were purchased from Sigma-Aldrich; Merck Millipore (Darmstadt, Germany). CP and QR were obtained from Dr Reddy's Laboratories, Ltd. (Hyderabad, India) and HiMedia Laboratories Pvt. Ltd. (Mumbai, India), respectively. General chemicals were purchased from Sigma-Aldrich; Merck Millipore, Sisco Research Laboratories Pvt. Ltd. (Mumbai, India) and Merck Ltd. India (Mumbai, India).

Animals. Male Wistar rats ( $\mathrm{n}=24$; weight, $180-250 \mathrm{~g}$ ) were acquired from the Central Animal House of Jamia Hamdard (New Delhi, India). The rats were acclimatized for a week prior to the initiation of the experiments. Animals were housed at a temperature of $22 \pm 2^{\circ} \mathrm{C}$ and a relative humidity of $65 \pm 10 \%$ under a 12-h light/dark cycle, and had ad libitum access to standard rodent food and deionized water. Experiments were performed according to the standard guidelines of Institutional Animal Ethics Committee of Jamia Hamdard (New Delhi, India). The study was approved by the Institutional Animal Ethics Committee of Jamia Hamdard.

Mitochondrial preparation. Mitochondria were isolated by differential centrifugation, as previously described (22). Briefly, liver from anaesthtized (Nembutal, $150 \mathrm{mg} / \mathrm{kg}$, i.p., Sigma-Aldrich) adult rats were excised and homogenized using a mechanical Potter Elvehjem homogenizer in an ice-cold isolation buffer containing $0.25 \mathrm{M}$ sucrose, $1 \mathrm{mM}$ EDTA adjusted with Tris to $\mathrm{pH} 7.4$, and centrifuged at $800 \mathrm{x}$ g for $5 \mathrm{~min}$ at $4^{\circ} \mathrm{C}$. The supernatant was centrifuged at $5,100 \mathrm{x}$ g for $4 \mathrm{~min}$ at $4^{\circ} \mathrm{C}$. Subsequently, the obtained pellet was resuspended in a $0.25 \mathrm{M}$ sucrose solution adjusted with Tris to $\mathrm{pH} 7.4$, and centrifuged at $12,300 \mathrm{x}$ g for $2 \mathrm{~min}$ at $4^{\circ} \mathrm{C}$. Finally, the pellet was resuspended in a $0.25 \mathrm{M}$ sucrose solution adjusted with Tris to $\mathrm{pH} 7.4$, centrifuged at $12,300 \mathrm{x} \mathrm{g}$ for $10 \mathrm{~min}\left(4^{\circ} \mathrm{C}\right)$ and resuspended in a buffer containing $0.25 \mathrm{M}$ sucrose, $0.5 \mathrm{mM}$ EDTA adjusted with Tris to $\mathrm{pH}$ 7.4. The protein concentration of the stock mitochondrial stock preparation was $4.5 \mathrm{mg} / \mathrm{ml}$, as determined by Waseem and Parvez (22).

Experimental design (pre-incubation). For in vitro investigations of CP-induced hepatic mitotoxicity and its modulation by $\mathrm{QR}$, mitochondrial samples were analyzed as following: Group I (untreated control), group II (QR), group III (CP) and group IV (CP with QR pre-treatment). In group IV, liver mitochondria were pre-treated with $50 \mu \mathrm{M} \mathrm{QR}$ at $37^{\circ} \mathrm{C}$ for $1 \mathrm{~h}$ prior to exposure to $100 \mu \mathrm{g} / \mathrm{ml} \mathrm{CP}$ for $1 \mathrm{~h} \mathrm{(22).} \mathrm{The}$ concentration of QR was selected according to previous in vitro studies on hepatic and non-hepatic cells $(17,21)$. The schedule was designed so that the end point of all groups occurred concurrently.

Evaluation of mitochondrial lipid peroxidation (LPO). LPO was quantified using the protocol described by Waseem and
Parvez (22). The reaction mixture consisted of $0.01 \mathrm{M}$ BHT, $6.7 \mathrm{mg} / \mathrm{ml}$ TBA, $1 \%$ chilled OPA and $250 \mu 1$ mitochondrial preparation. The rate of LPO was determined as nmoles thiobarbituric acid reactive substances formed/h/g of tissue using a molar extinction coefficient of $1.56 \times 10^{5} \mathrm{M}^{-1} \mathrm{~cm}^{-1}$.

Estimation of mitochondrial protein oxidation (PC). PC content was assessed using the protocol described by Waseem and Parvez (22). Mitochondria $(2 \mathrm{mg} / \mathrm{ml})$ were mixed with $0.01 \mathrm{M} \mathrm{DNPH}$ in $2 \mathrm{M} \mathrm{HCl}$ for $1 \mathrm{~h}$ at room temperature and precipitated with $60 \mathrm{mg} / \mathrm{ml}$ TCA. The protein pellet was washed two or three times with a solution of ethanol/ethyl acetate (1:1 ratio, v/v). Proteins were subsequently solubilized in $6 \mathrm{M}$ guanidine hydrochloride and $50 \%$ formic acid, and centrifuged at $10,000 \mathrm{x}$ g for $5 \mathrm{~min}$ at $4^{\circ} \mathrm{C}$. The carbonyl level was quantified spectrophotometrically at a wavelength of $360 \mathrm{~nm}$. Results were expressed as nmoles DNPH incorporated $/ \mathrm{mg}$ protein using a molar extinction coefficient of $21,000 \mathrm{M}^{-1} \mathrm{~cm}^{-1}$.

Determination of mitochondrial GSH. The GSH level was assessed according to the procedure of Tabassum et al (23). Mitochondria were primarily precipitated with $40 \mathrm{mg} / \mathrm{ml}$ sulphosalicylic acid and were maintained at $4^{\circ} \mathrm{C}$ for $1 \mathrm{~h}$, followed by centrifugation at $1,500 \times \mathrm{g}$ for $15 \mathrm{~min}$ at $4^{\circ} \mathrm{C}$. The reaction mixture (total volume, $3 \mathrm{ml}$ ) consisted of $100 \mathrm{mM}$ sodium phosphate buffer (pH 7.4), $0.01 \mathrm{M}$ DTNB and $400 \mu \mathrm{l}$ mitochondria stock preparation. The absorbance of the reacted product was measured at a wavelength of $412 \mathrm{~nm}$ on a dual-beam spectrophotometer. The GSH content was expressed as $\mu$ moles GSH/g tissue.

Estimation of mitochondrial non-protein-bound thiols $(N P-S H)$. NP-SH levels were measured according to the protocol of Waseem and Parvez (22), with certain minor modifications. Mitochondria (1-2 $\mathrm{mg} / \mathrm{ml})$ were precipitated with $400 \mathrm{mg} / \mathrm{ml}$ TCA and subsequently centrifuged at $3000 \mathrm{x} \mathrm{g}$ for $15 \mathrm{~min}$ at $4^{\circ} \mathrm{C}$. Following this, $400 \mathrm{mM}$ Tris buffer (pH 8.9) and $10 \mathrm{mM}$ DTNB were added to the supernatant. Absorbance was measured at a wavelength of $412 \mathrm{~nm}$, and results were expressed as $\mu$ moles NP-SH/g tissue using a molar extinction coefficient of $13,100 \mathrm{M}^{-1} \mathrm{~cm}^{-1}$.

Activity of mitochondrial glutathione S-transferase (GST). The method of Waseem and Parvez (22) was used to evaluate GST activity, with certain minor modifications. The reaction mixture consisted of $100 \mathrm{mM}$ sodium phosphate buffer (pH 7.4), $10 \mathrm{mM} \mathrm{GSH}, 10 \mathrm{mM}$ CDNB and $100 \mu \mathrm{l}$ mitochondrial suspension. Absorbance was measured at a wavelength of $340 \mathrm{~nm}$ at $30 \mathrm{sec}$ intervals for $3 \mathrm{~min}$, and results were expressed as $\mu$ moles CDNB conjugate formed $/ \mathrm{min} / \mathrm{mg}$ protein using a molar extinction coefficient of $9.6 \times 10^{3} \mathrm{M}^{-1} \mathrm{~cm}^{-1}$.

Kinetics of mitochondrial glutathione peroxidase (GPX). The method of Waseem and Parvez (22) was used to evaluate GPx activity, with certain minor modifications. The reaction mixture consisted of $100 \mathrm{mM}$ sodium phosphate buffer, $1 \mathrm{mM}$ EDTA, $1 \mathrm{mM}$ sodium azide, $10 \mathrm{mM}$ GSH, $2 \mathrm{mM}$ NADPH, $10 \mu 1 \mathrm{H}_{2} \mathrm{O}_{2}(10.32 \mathrm{M})$ and $4-5 \mathrm{mg} / \mathrm{ml}$ mitochondrial suspension, in a final volume of $2 \mathrm{ml}$. NADPH oxidation was measured 
kinetically at a wavelength of $340 \mathrm{~nm}$ at $30 \mathrm{sec}$ intervals for $3 \mathrm{~min}$. The enzyme activity was calculated as nmoles NADPH oxidized $/ \mathrm{min} / \mathrm{mg}$ protein, using a molar extinction coefficient of $6.22 \times 10^{3} \mathrm{M}^{-1} \mathrm{~cm}^{-1}$.

Activity of mitochondrial manganese-superoxide dismutase (Mn-SOD). Mn-SOD activity was assessed according to the procedure of Waseem and Parvez (23). Mitochondria (180 $\mu \mathrm{l}$ stock preparation) were treated with $0.05 \mathrm{M}$ glycine buffer (pH 10.4) and $20 \mathrm{mg} / \mathrm{ml}$ epinephrine. The enzymatic activity was measured kinetically at a wavelength of $480 \mathrm{~nm}$ at $30 \mathrm{sec}$ intervals for $3 \mathrm{~min}$. The activity was expressed as nmoles epinephrine protected from oxidation $/ \mathrm{min} / \mathrm{mg}$ protein using a molar extinction coefficient of $4,020 \mathrm{M}^{-1} \mathrm{~cm}^{-1}$.

Activity of complex I (NADH-dehydrogenase). The procedure of King and Howard (24) was used to measure NADH-dehydrogenase activity, with certain minor modifications. The reaction mixture consisted of $600 \mu \mathrm{M}$ DCIP, $2 \mathrm{mM}$ glycyl glycine buffer, $600 \mu \mathrm{M}$ NADH and $100 \mu \mathrm{l}$ mitochondrial stock preparation. The absorbance was measured at a wavelength of $600 \mathrm{~nm}$. The enzyme activity was expressed as nmoles NADH oxidized $/ \mathrm{min} / \mathrm{mg}$ protein using a molar extinction coefficient of $21,000 \mathrm{M}^{-1} \mathrm{~cm}^{-1}$.

Activity of complex II (succinate dehydrogenase). Succinate dehydrogenase activity was assessed according to the protocol of Waseem and Parvez (22). The reaction mixture consisted of $100 \mathrm{mM}$ phosphate buffer (pH 7.4), $10 \mathrm{mg} / \mathrm{ml} \mathrm{BSA,0.0015} \mathrm{M}$ potassium ferricynanide, $15 \mathrm{mM}$ sodium succinate and $100 \mu \mathrm{l}$ mitochondrial stock preparation. The absorbance was measured for $3 \mathrm{~min}$ at a wavelength of $420 \mathrm{~nm}$. The enzyme activity was expressed as nmoles succinate produced $/ \mathrm{min} / \mathrm{mg}$ protein using a molar extinction coefficient of $1,000 \mathrm{M}^{-1} \mathrm{~cm}^{-1}$.

Activity of complex III (mitochondrial dehydrogenase, MTT). The MTT reduction rate was used to measure the mitochondrial respiratory complex activity according to the method of Kamboj et al (25), with certain minor modifications. Briefly, $100 \mu \mathrm{g}$ mitochondrial preparation was suspended in $1.5 \mathrm{ml}$ eppendorf tubes with ice cold buffer $\mathrm{C}$, and incubated at $37^{\circ} \mathrm{C}$ in the presence of $20 \mu \mathrm{l}$ of MTT $(0.1 \mathrm{mg} / \mathrm{ml})$. After $30 \mathrm{~min}$ incubation period, tubes were centrifuged at $1,000 \times \mathrm{g}$ for $10 \mathrm{~min}$, and the blue formazan crystals were solubilised in $1 \mathrm{ml}$ DMSO. The absorbance was measured at $595 \mathrm{~nm}$. The results were expressed as nmoles formazan formed $/ \mathrm{min} / \mathrm{mg}$ protein using a molar extinction coefficient of $51,000 \mathrm{M}^{-1} \mathrm{~cm}^{-1}$.

Activity of complex $V$ (total ATPase). Total ATPase activity was quantified by measuring the hydrolysis rate of ATP to ADP and inorganic phosphate (Pi), according to the protocol of Waseem and Parvez (22), with certain minor modifications. Mitochondria (0.2 $\mathrm{mg}$ stock preparation) were incubated in ATPase buffer (50 mM Tris and $\left.5 \mathrm{mM} \mathrm{MgCl}_{2}, \mathrm{pH} 7.5\right)$ at $37^{\circ} \mathrm{C}$ with $5 \mathrm{mM}$ ATP for $10 \mathrm{~min}$. The reaction was terminated via the addition of $100 \mathrm{mg} / \mathrm{ml} \mathrm{TCA}$. The suspension was subsequently centrifuged at $3,000 \mathrm{x}$ g for $20 \mathrm{~min}$ at $4^{\circ} \mathrm{C}$, and the supernatants were mixed with $0.5 \mathrm{ml}$ distilled water. The reaction measuring $\mathrm{Pi}$ production was initiated by adding a mixture containing $720 \mathrm{mM}$ sodium bisulfite, $41.6 \mathrm{mM}$ sodium sulfite and $10 \mathrm{mM}$ ANSA. The enzyme activity was measured at $660 \mathrm{~nm}$ and expressed as $\mu \mathrm{g}$ Pi liberated/min/mg protein.

Protein content determination. The protein content of mitochondria was assessed according to the protocol described by Lowry et al (26). BSA (1 mg/ml) served as the standard.

Statistical analysis. Results are expressed as the mean \pm standard error. Data were analyzed using one-way analysis of variance followed by Tukey's post hoc test. $\mathrm{P}<0.05$ was considered to indicate a statistically significant difference. Statistical analyses were performed using GraphPad Prism software version 5 (GraphPad Software, Inc., La Jolla, CA, USA).

\section{Results}

$Q R$ inhibits the CP-induced increase in LPO and PC levels. $\mathrm{CP}$ treatment (group III) significantly increased LPO (Fig. 1A) and PC (Fig. 1B) levels ( $\mathrm{P}<0.001$, respectively) compared with the control group (group I). QR pre-treatment (group IV) significantly decreased LPO and PC levels $(\mathrm{P}<0.001)$ compared with CP treatment alone (group III). QR treatment alone (group II) significantly decreased LPO levels compared with the control group $(\mathrm{P}<0.01)$; however, it had no significant effect on PC levels.

QR attenuates the CP-induced decrease in GSH and NP-SH levels. CP treatment significantly decreased GSH (Fig. 2A) and NP-SH (Fig. 2B) levels in liver mitochondria compared with the control group $(\mathrm{P}<0.001)$. $\mathrm{QR}$ pre-treatment significantly attenuated these effects $(\mathrm{P}<0.001) . \mathrm{QR}$ alone significantly increased GSH levels compared with the control group $(\mathrm{P}<0.001)$; however, it had no significant effect on NP-SH content.

$Q R$ protects against the CP-induced decrease in glutathione metabolizing enzyme levels. CP treatment significantly decreased GST (Fig. 3A) and GPx (Fig. 3B) activities compared with the control group $(\mathrm{P}<0.01$ and $\mathrm{P}<0.001$, respectively). $\mathrm{QR}$ pre-treatment significantly attenuated these effects. QR alone had no significant effects on GST or GPx activities.

QR modulates the CP-induced decrease in Mn-SOD activity. CP treatment significantly decreased Mn-SOD activity (Fig. 4) in liver mitochondria compared with the control group $(\mathrm{P}<0.01)$. QR pre-treatment significantly abrogated this effect $(\mathrm{P}<0.01)$. $\mathrm{R}$ alone had no significant effect of Mn-SOD.

$Q R$ ameliorates the CP-induced decrease in complex I and II enzyme activities. $\mathrm{CP}$ treatment significantly reduced NADH dehydrogenase (Fig. 5A) and succinate dehydrogenase (Fig. 5B) activities compared with the control group $(\mathrm{P}<0.01$ and $\mathrm{P}<0.001$, respectively). $\mathrm{QR}$ pre-treatment significantly attenuated these effects $(\mathrm{P}<0.001)$. QR alone significantly increased succinate dehydrogenase activity compared with the control group $(\mathrm{P}<0.01)$; however, it had no significant effect on NADH dehydrogenase activity.

QR modulates the CP-induced inhibition of complex III and $V$ enzyme activities. CP treatment significantly decreased MTT 


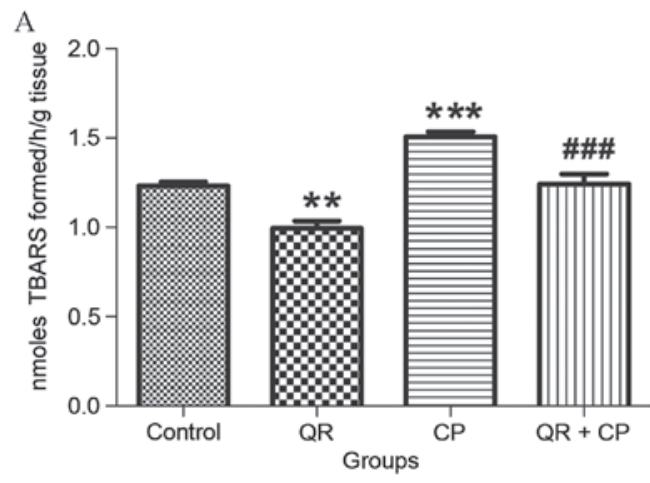

B

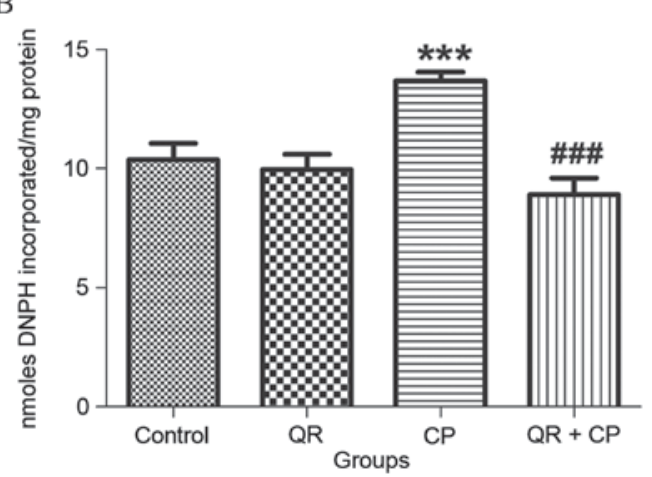

Figure 1. Effect of $100 \mu \mathrm{g} / \mathrm{ml} \mathrm{CP}$ and $50 \mu \mathrm{M}$ QR on LPO and PC levels in rat liver mitochondria. QR inhibited the CP-induced increase in (A) LPO and (B) PC levels. Results are expressed as nmoles TBARS formed/h/mg protein and nmoles DNPH incorporated/mg protein. Data are expressed as the mean \pm standard error $(\mathrm{n}=6) .{ }^{* *} \mathrm{P}<0.01$ and ${ }^{* * *} \mathrm{P}<0.001$ vs. control;

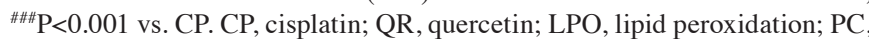
protein oxidation; TBARS, thiobarbituric acid reactive substances; DNPH, 2,4-dinitrophenyl hydrazine.

ability (Fig. 6A) and total ATPase activity (Fig. 6B) compared with the control group $(\mathrm{P}<0.01$, respectively). $\mathrm{QR}$ pre-treatment significantly abrogated these effects $(\mathrm{P}<0.01$ and $\mathrm{P}<0.001$, respectively). QR alone significantly increased MTT ability compared with the control group $(\mathrm{P}<0.05)$; however, it had no significant effect on total ATPase activity.

\section{Discussion}

$\mathrm{CP}$ is a platinum-based heavy metal that is a chemotherapeutic agent used for the treatment of various cancers (22). However, the application of CP is limited as a result of the hepatotoxicity that has been demonstrated to develop following treatment in various animal models. Our previous study (27) was the first to observe that $\mathrm{CP}$ significantly elevated LPO levels in isolated rat liver mitochondria. LPO has been suggested as a primary underlying mechanism by which free radicals damage cells. The significant increase in LPO levels may be due to its poor antioxidant defenses or the non-stimulation of antioxidant enzymes, due to oxidative stress. In addition, increased LPO levels or a reduction in antioxidants have been associated with complex IV activity decrease, which may ultimately result in mitochondria-dependent apoptosis (28). In the present study, QR pre-treatment was observed to significantly restore LPO levels and alter antioxidant status. QR decreased the oxidative stress marker LPO via reactive oxygen species (ROS) scavenging (29). In
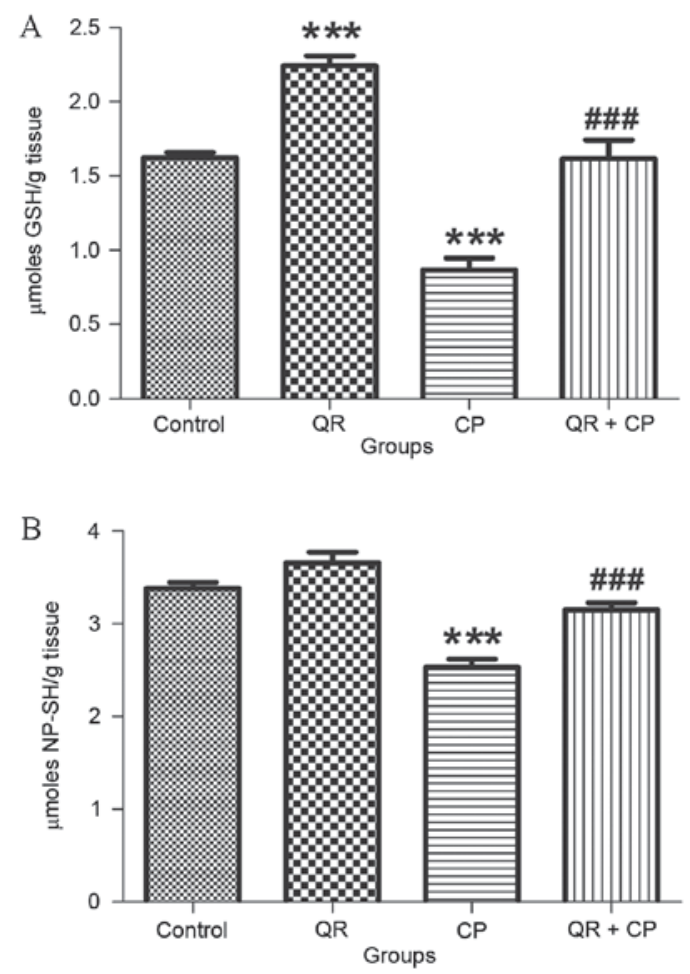

Figure 2. Effect of $100 \mu \mathrm{g} / \mathrm{ml} \mathrm{CP}$ and $50 \mu \mathrm{M}$ QR on GSH and NP-SH contents in rat liver mitochondria. QR attenuated the CP-induced decrease in (A) GSH and (B) NP-SH levels. Results are expressed as $\mu$ moles GSH/g tissue and $\mu$ moles NP-SH/g tissue. Data are expressed as the mean \pm standard error $(\mathrm{n}=6) .{ }^{* * *} \mathrm{P}<0.001$ vs. control; ${ }^{\# \#} \mathrm{P}<0.001$ vs. CP. CP, cisplatin; $\mathrm{QR}$, quercetin; $\mathrm{GSH}$, reduced glutathione; NP-SH, non-protein-bound thiols.
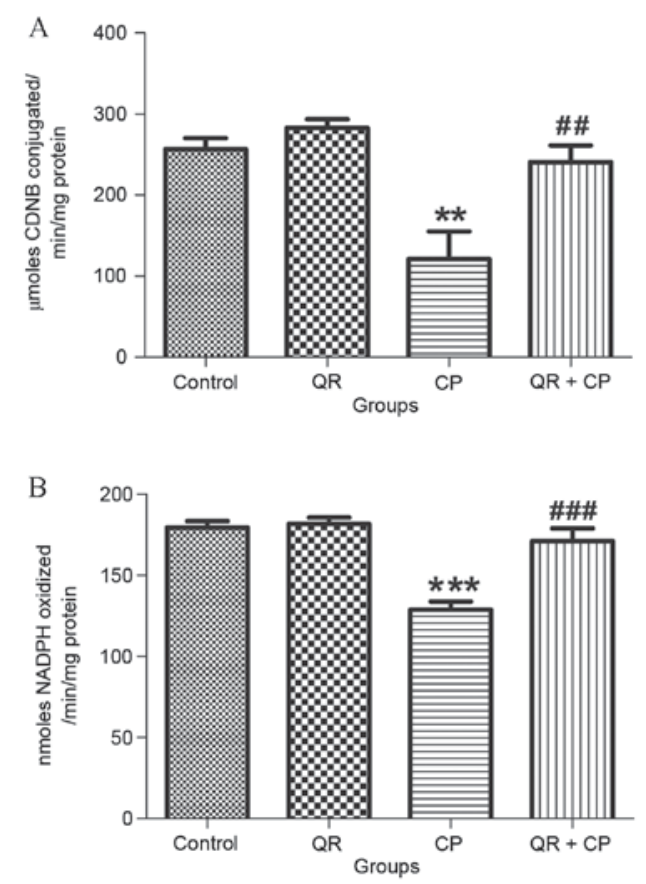

Figure 3. Effect of $100 \mu \mathrm{g} / \mathrm{ml} \mathrm{CP}$ and $50 \mu \mathrm{M}$ QR on GST and GPx activities in rat liver mitochondria. $\mathrm{QR}$ protected against the $\mathrm{CP}$-induced decrease in $(\mathrm{A})$ GST and (B) GPx activities. Results are expressed as $\mu$ moles CDNB conjugated $/ \mathrm{min} / \mathrm{mg}$ protein and nmoles NADPH oxidized $/ \mathrm{min} / \mathrm{mg}$ protein. Data are expressed as the mean \pm standard error $(\mathrm{n}=6) .{ }^{* *} \mathrm{P}<0.01$ and ${ }^{* * * *} \mathrm{P}<0.001$ vs. control; ${ }^{\#} \mathrm{P}<0.01$ and ${ }^{\# \# \#} \mathrm{P}<0.001$ vs. CP. CP, cisplatin; QR, quercetin; GST, glutathione S-transferase; GPx, glutathione peroxidase; CDNB, 1-chloro-2, 4 dinitrobenzene; NADPH, nicotinamide adenine dinucleotide phosphate reduced tetra sodium salt. 


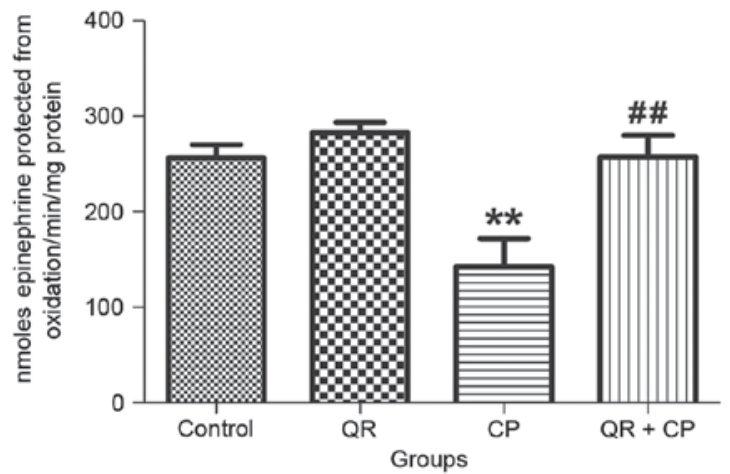

Figure 4. Effect of $100 \mu \mathrm{g} / \mathrm{ml} \mathrm{CP}$ and $50 \mu \mathrm{M}$ QR on Mn-SOD activity in rat liver mitochondria. QR modulated the CP-induced decrease in Mn-SOD activity. Results are expressed as nmoles epinephrine protected from oxidation $/ \mathrm{min} / \mathrm{mg}$ protein. Data are expressed as the mean \pm standard error $(\mathrm{n}=6)$. ${ }^{* *} \mathrm{P}<0.01$ vs. control; ${ }^{\# \#} \mathrm{P}<0.01$ vs. $\mathrm{CP}$. CP, cisplatin; $\mathrm{QR}$, quercetin; Mn-SOD, manganese-superoxide dismutase.
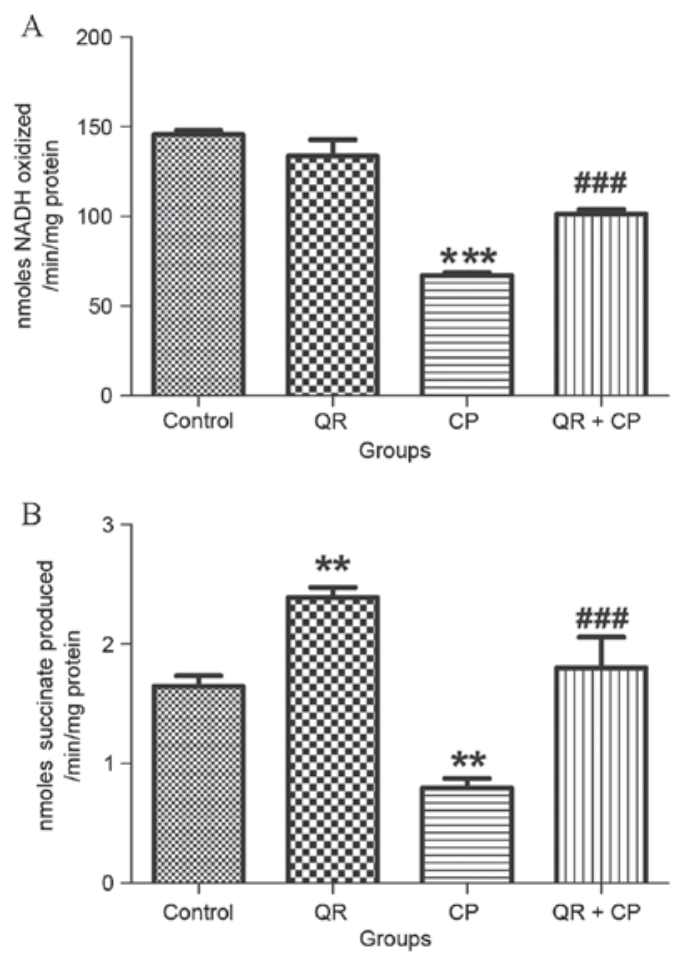

Figure 5. Effect of $100 \mu \mathrm{g} / \mathrm{ml} \mathrm{CP}$ and $50 \mu \mathrm{M}$ QR on NADH-dehydrogenase and succinate dehydrogenase activities in rat liver mitochondria. QR attenuated the CP-induced decrease in (A) NADH-dehydrogenase and (B) succinate dehydrogenase activites. Results are expressed as nmoles NADH oxidized $/ \mathrm{min} / \mathrm{mg}$ protein and nmoles succinate oxidized $/ \mathrm{min} / \mathrm{mg}$ protein. Data are expressed as the mean \pm standard error $(n=6) .{ }^{* *} \mathrm{P}<0.01$ and ${ }^{* * *} \mathrm{P}<0.001$ vs. control; ${ }^{\# \# *} \mathrm{P}<0.001$ vs. CP. CP, cisplatin; QR, quercetin; $\mathrm{NADH}$, nicotinamide adenine dinucleotide reduced

the present study, QR prevented the $\mathrm{CP}$-induced increase in LPO levels, which may sustain cellular integrity and defense against damage due to free radicals.

PC is an extensively used biomarker and the predominant indicator of protein carbonyl accumulation and protein oxidation. The results of the present study support this, as PC content increased in isolated liver mitochondria on exposure to $\mathrm{CP}$. The biomarker of oxidative protein damage is protein
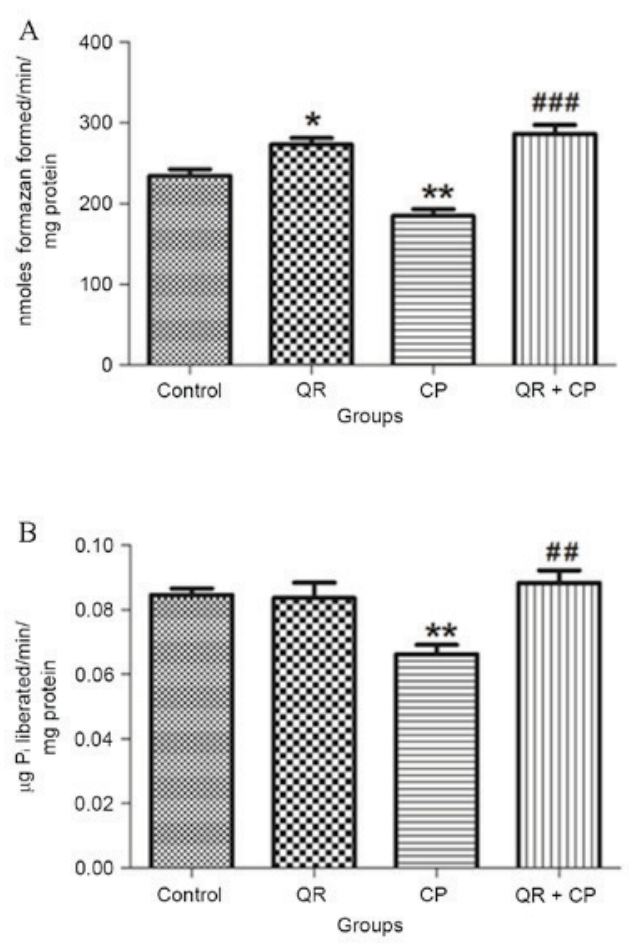

Figure 6. Effect of $100 \mu \mathrm{g} / \mathrm{ml} \mathrm{CP}$ and protective effect of $50 \mu \mathrm{M}$ QR on MTT level and total ATPase activity in rat liver mitochondria. QR abrogated the CP-induced decrease in (A) MTT ability and (B) total ATPase activity. Results are expressed as nmoles formazan formed $/ \mathrm{min} / \mathrm{mg}$ protein and $\mu \mathrm{g} \mathrm{Pi}$ liberated $/ \mathrm{min} / \mathrm{mg}$ protein. Data are expressed as the mean \pm standard error $(\mathrm{n}=6) .{ }^{*} \mathrm{P}<0.05$ and $^{* *} \mathrm{P}<0.01$ vs. control; ${ }^{\# \#} \mathrm{P}<0.01$ and ${ }^{\# \# \#} \mathrm{P}<0.001$ vs. $\mathrm{CP} . \mathrm{CP}$ cisplatin; $\mathrm{QR}$, quercetin; $\mathrm{Pi}$, inorganic phosphate.

carbonylation, as a result of xenobiotically-induced oxidative stress. QR pre-treatment significantly restored PC contents in isolated liver mitochondria. The modulatory role of natural compounds on protein carbonylation has been demonstrated by previous studies (30).

GSH is the primary antioxidant molecule and detoxifies various types of endogenous and exogenous toxicants, including CP, via GSH adducts formation (22). Additionally, the redox cycle of GSH, consisting of GSH, GPx and glutathione reductase, is crucial in scavenging the ROS generated by $\mathrm{CP}$, to protect cells from potential toxicity and carcinogenesis (31). In the present study, CP significantly reduced the levels of GSH in liver mitochondria. QR treatment increased mitochondrial GSH levels and pre-treatment with QR inhibited the CP-induced reduction in GSH levels. These results suggested that cells protected by QR pre-treatment are less susceptible to $\mathrm{CP}$-induced mitochondrial oxidative stress.

In the present study, NP-SH levels were significantly decreased in isolated liver mitochondria by CP treatment, which is in accordance with the GSH results, as GSH levels in liver tissue comprise $>90 \%$ of the NP-SH pool. It is recognized that the total cellular thiol pool is integral in homeostasis and is additionally important in oxidative physiology. Treatment with QR increased the mitochondrial NP-SH levels (32) and QR pre-treatment significantly attenuated the CP-induced reduction in NP-SH levels, suggesting that cells protected by QR pre-treatment are less susceptible to CP-induced mitochondrial oxidative stress. 
GSTs are a group of enzymes that conjugate GSH to structurally diverse electrophilic compounds. GST catalyzes the conjugation of GSH via a sulfhydryl group to electrophilic centers on a wide variety of substrates. GST is responsible for scavenging organic peroxides, and endogenous and exogenous electrophiles. Diverse forms of GST have been revealed to bind $\mathrm{CP}$ in vivo and in vitro (33). In the present study, it was observed that CP significantly decreased GST activity in isolated liver mitochondria. Reduced mitochondrial GST activity may be associated with an elevation in ROS generation following tissue injury (22). In the present study, QR pre-treatment restored the activity of GST. This may provide protection from oxidative stress due to excess $\mathrm{O}_{2}$ and $\mathrm{H}_{2} \mathrm{O}_{2}$. Mitochondrial oxidative damage occurs as a results of the respiratory chain; complex I and III are the foremost sources of superoxide anion $\left(\mathrm{O}_{2}^{-}\right)(22)$. Energy or ATP production by oxidative phosphorylation takes place in mitochondria and is catalyzed by membrane-bound protein complexes, namely NADH-dehydrogenase (complex I), succinate dehydrogenase (complex II), cytochrome c oxidoreductase (complex III) and total ATPases. Succinate dehydrogenase contributes only by transferring electrons to the electron transport chain (ETC), whereas NADH-dehydrogenase is associated with proton translocation and electron transfer. The defect in any of the enzyme complexes responsible for oxidative metabolism may lead to mitochondrial cytopathy (22) and to the opening of the mitochondrial permeability transition pore that allows the membrane potential to dissipate resulting in uncoupling of oxidative phosphorylation and therefore impaired cellular ATP production. Previous studies have demonstrated that mitochondrial dysfunctions are involved in mitochondrial toxicity induced by platinum-based chemotherapeutic agents, including CP $(2,22)$. The results of the present study suggested that $\mathrm{CP}$ inactivated mitochondrial complex enzymes, as indicated by a reduction in NADH-dehydrogenase and succinate dehydrogenase activities, MTT ability and ATPase activity. QR pre-treatment significantly protected these complex enzymes. QR has been revealed to modulate mitochondrial dysfunction in rodents and its property as an antioxidant is hypothesized to be responsible for its protective effects in mitochondria $(5,9)$.

The alterations in the activities of mitochondrial complex enzymes may be involved in hepatotoxicity. This may be as a result of free radicals, as well as a reduction in mitochondrial transcription and translation. Furthermore, it has been revealed that mitochondrial activity interference is associated with effects on complex enzymes, particularly complexes I and III of the ETC, which result in increased mitochondrial electron leakage. QR pre-treatment restored the activity of complex enzymes in liver mitochondria. This may be due to the increase in the scavenging and inactivation of $\mathrm{H}_{2} \mathrm{O}_{2}$ and hydroxyl radicals caused by QR (34). Previous studies have demonstrated that $\mathrm{QR}$ protects against mitochondrial oxidative stress and actively increases biologically active mitochondria in cells, following treatment with the concentration used in the present study $(5,9)$.

In conclusion, the results of the present study suggested that CP exerts hepatotoxic effects through the induction of oxidative stress, indicated by the alterations in the concentrations of mitochondrial complex enzymes and non-enzymatic antioxidants. The protective effect of QR was associated with its antioxidant potential, as it potentially acts as a free radical scavenger, LPO inhibitor and GSH activator. Further studies, particularly molecular experiments, are required to investigate the mitigatory effect of QR on mitochondria-mediated anticancer drug toxicities.

\section{Acknowledgements}

The present study was supported by the University Grants Commission Basic Science Research (grant no. F-7/91/2007, to M.W.), the Department of Biotechnology, Government of India (DBT BioCARe Program; grant no. BT/Bio-CARe/01/10219/2013-14, to H.T.), the University Grants Commission, New Delhi, Government of India [grant no. F. 41-1286/2012 (SR), to S.P.] and the Department of Science and Technology for funding under PURSE program (to J.H., 2016).

\section{References}

1. Kellokumpu-Lehtinen PL, Hjälm-Eriksson M, Thellenberg-Karlsson C, Aström L, Franzen L, Marttila T, Seke M, Taalikka M and Ginman C; SPCG-13: Toxicity in patients receiving adjuvant docetaxel + hormonal treatment after radical radiotherapy for intermediate or high-risk prostate cancer: A preplanned safety report of the SPCG-13 trial. Prostate Cancer Prostatic Dis 15: 303-307, 2012.

2. Kim JH, Jeong SJ, Kwon HY, Park SY, Lee HJ, Lee HJ, Lieske JC and Kim SH: Decursin prevents cisplatin-induced apoptosis via the enhancement of antioxidant enzymes in human renal epithelial cells. Biol Pharm Bull 33: 1279-1284, 2010

3. Saad JS, Benedetti M, Natile G and Marzilli LG: Basic coordination chemistry relevant to DNA adducts formed by the cisplatin anticancer drug. NMR studies on compounds with sterically crowded chiral ligands. Inorg Chem 49: 5573-5583, 2010.

4. Mantri Y, Lippard SJ and Baik MH: Bifunctional binding of cisplatin to DNA: Why does cisplatin form 1,2-intrastrand cross-links with ag but not with GA? J Am Chem Soc 129: 5023-5030, 2007.

5. Baruah H, Wright MW and Bierbach U: Solution structural study of a DNA duplex containing the guanine-N7 adduct formed by a cytotoxic platinum-acridine hybrid agent. Biochemistry 44 : 6059-6070, 2005.

6. Khan N: Recent advancements in diagnostic tools in mitochondrial energy metabolism diseases. Adv Med Sci 61: 244-248, 2016.

7. Iwata $T$, Nishiyama N, Nagano K, Izumi N, Mizuguchi S, Tsukioka T, Morita R, Chung K, Hanada S and Inoue K: Role of pulmonary resection in the diagnosis and treatment of limited-stage small cell lung cancer: Revision of clinical diagnosis based on findings of resected specimen and its influence on survival. Gen Thorac Cardiovasc Surg 60: 43-52, 2012.

8. Burgeiro A, Gajate C, Dakirel H, Villa-Pulgarín JA, Oliveira PJ and Mollinedo F: Involvement of mitochondrial and B-RAF/ERK signaling pathways in berberine-induced apoptosis in human melanoma cells. Anticancer Drugs 22: 507-518, 2011.

9. Zicca A, Cafaggi S, Mariggiò MA, Vannozzi MO, Ottone M, Bocchini V, Caviglioli G and Viale M: Reduction of cisplatin hepatotoxicity by procainamide hydrochloride in rats. Eur $\mathrm{J}$ Pharmacol 442: 265-272, 2002.

10. Liu JJ, Galettis P, Farr A, Maharaj L, Samarasinha H, McGechan AC, Baguley BC, Bowen RJ, Berners-Price SJ and McKeage MJ: In vitro antitumour and hepatotoxicity profiles of $\mathrm{Au}(\mathrm{I})$ and $\mathrm{Ag}(\mathrm{I})$ bidentate pyridyl phosphine complexes and relationships to cellular uptake. J Inorg Biochem 102: 303-310, 2008.

11. Zhang X, Yeung ED, Wang J, Panzhinskiy EE, Tong C, Li W and $\mathrm{Li}$ J: Isoliquiritigenin, a natural anti-oxidant, selectively inhibits the proliferation of prostate cancer cells. Clin Exp Pharmacol Physiol 37: 841-847, 2010.

12. Pandey KB and Rizvi SI: Plant polyphenols as dietary antioxidants in human health and disease. Oxid Med Cell Longev 2: 270-278, 2009

13. Ciftci O, Ozdemir I, Vardi N, Beytur A and Oguz F: Ameliorating effects of quercetin and chrysin on 2,3,7,8-tetrachlorodibenzop-dioxin-induced nephrotoxicity in rats. Toxicol Ind Health 28: 947-954, 2012. 
14. Matouk AI, Taye A, Heeba GH and El-Moselhy MA: Quercetin augments the protective effect of losartan against chronic doxorubicin cardiotoxicity in rats. Environ Toxicol Pharmacol 36: 443-450, 2013

15. Haleagrahara N, Siew CJ and Ponnusamy K: Effect of quercetin and desferrioxamine on 6-hydroxydopamine (6-OHDA) induced neurotoxicity in striatum of rats. J Toxicol Sci 38: 25-33, 2013.

16. Sekaran S, Kandaswamy S, Gunasekaran K, Perumal E, Afsar Basha FY, Madhan Mohan BJ and Jagadeesan A: Protective role of quercetin on polychlorinated biphenyls (Aroclor-1254) induced oxidative stress and apoptosis in liver of adult male rats. J Biochem Mol Toxicol 26: 522-532, 2012.

17. Kallio J, Jaakkola M, Mäki M, Kilpeläinen P and Virtanen V: Vitamin C inhibits staphylococcus aureus growth and enhances the inhibitory effect of quercetin on growth of Escherichia coli in vitro. Planta Med 78: 1824-1830, 2012

18. Di Cesare Mannelli L, Zanardelli M, Failli P and Ghelardini C: Oxaliplatin-induced neuropathy: Oxidative stress as pathological mechanism. Protective effect of silibinin. J Pain 13: 276-284, 2012.

19. Youn H, Jeong JC, Jeong YS, Kim EJ and Um SJ: Quercetin potentiates apoptosis by inhibiting nuclear factor-kappaB signaling in H460 lung cancer cells. Biol Pharm Bull 36: 944-951, 2013.

20. Tang Y, Gao C, Xing M, Li Y, Zhu L, Wang D, Yang X, Liu L and Yao P: Quercetin prevents ethanol-induced dyslipidemia and mitochondrial oxidative damage. Food Chem Toxicol 50: 1194-1200, 2012

21. Jakubowicz-Gil J, Langner E, Wertel I, Piersiak T and Rzeski W: Temozolomide, quercetin and cell death in the MOGGCCM astrocytoma cell line. Chem Biol Interact 188: 190-203, 2010.

22. Waseem M and Parvez S: Neuroprotective activities of curcumin and quercetin with potential relevance to mitochondrial dysfunction induced by oxaliplatin. Protoplasma 253: 417-430, 2016.

23. Tabassum H, Parvez S, Pasha ST, Banerjee BD and Raisuddin S: Protective effect of lipoic acid against methotrexate-induced oxidative stress in liver mitochondria. Food Chem Toxicol 48 : 1973-1979, 2010

24. King TE and Howard RL: Preparations and properties of soluble NADH dehydrogenases from cardiac muscle. Methods Enzymol 10: 275-294, 1967.
25. Kamboj SS and Sandhir R: Protective effect of N-acetylcysteine supplementation on mitochondrial oxidative stress and mitochondrial enzymes in cerebral cortex of streptozotocin-treated diabetic rats. Mitochondrion 11: 214-222, 2011.

26. Lowry OH, Rosebrough NJ, Farr AL and Randal RJ: Protein measurement with the Folin phenol reagent. J Biol Chem 193 265-275, 1951.

27. Waseem M, Bhardwaj M, Tabassum H, Raisuddin S and Parvez S: Cisplatin hepatotoxicity mediated by mitochondrial stress. Drug Chem Toxicol 38: 452-459, 2015.

28. Badary OA, Abdel-Maksoud S, Ahmed WA and Owieda GH: Naringenin attenuates cisplatin nephrotoxicity in rats. Life Sci 76: 2125-2135, 2005 .

29. Tucci P, Cione E, Perri M and Genchi G: All-trans-retinoic acid induces apoptosis in Leydig cells via activation of the mitochondrial death pathway and antioxidant enzyme regulation. J Bioenerg Biomembr 40: 315-323, 2008.

30. Singh R and Sharma P: Hepatoprotective effect of curcumin on lindane-induced oxidative stress in male Wistar rats. Toxicol Int 18: 124-129, 2011.

31. Fedorova M, Bollineni RC and Hoffmann R: Protein carbonylation as a major hallmark of oxidative damage: Update of analytical strategies. Mass Spectrom Rev 33: 79-97, 2014.

32. Hanigan $\mathrm{MH}$ and Devarajan P: Cisplatin nephrotoxicity: Molecular mechanisms. Cancer Ther 1: 47-61, 2003.

33. Ognjanović BI, Djordjević NZ, Matić MM, Obradović JM, Mladenović JM, Stajn AS and Saičić ZS: Lipid peroxidative damage on Cisplatin exposure and alterations in antioxidant defense system in rat kidneys: A possible protective effect of selenium. Int J Mol Sci 13: 1790-1803, 2012.

34. Chen YR, Chen CL, Zhang L, Green-Church KB and Zweier JL: Superoxide generation from mitochondrial NADH dehydrogenase induces self-inactivation with specific protein radical formation. J Biol Chem 280: 37339-37348, 2005. 